\title{
QU
}

\section{APLICAÇÃO DO JOGO “BARALHO LIGANTE” COMO RECURSO FACILITADOR NO ENSINO DE QUÍMICA}

* FREITAS, P. V. J. (IFRN); COSTA, M. A. (IFRN); REINALDO, S. M. A. S. (EEPAD); ALVES, L. A. (IFRN); BERTINI, L. M. (IFRN); FERNANDES, P. R. N. (IFRN)

\section{RESUMO}

O presente trabalho busca relatar a importância da utilização de jogos lúdicos para melhorar o processo de ensino e aprendizagem, onde essa ferramenta poderá contribuir para esse processo e para o melhor entendimento do conteúdo ligações químicas podendose obter resultados satisfatórios diante dessa metodologia utilizada e assim contribuir no ensino de química.

PALAVRAS-CHAVE: Jogos didáticos, metodologia diferenciada, ensino de química.

\section{SEMINARS FOR USE AS MEANS TRAINER IN THE PROCESS OF LEARNING TEACHING CHEMISTRY}

This study aims to report the importance of using educational games to improve teaching and learning, where this tool can contribute to this process and to better understand the contents of chemical bonds can be obtained satisfactory results on this methodology and so contribute to the teaching of chemistry.

KEY-WORDS: Didactic games, different methodology, chemistry teaching. 


\section{APLICAÇÃO DO JOGO “BARALHO LIGANTE” COMO RECURSO FACILITADOR NO ENSINO DE QUÍMICA}

\section{INTRODUÇÃO}

O uso dos materiais didáticos na sala de aula torna o processo à aprendizagem mais eficaz, trazendo a melhor interação professor - aluno de maneira versátil e agradável sempre com objetivo de proporcionar o melhor ensino do Professor e o melhor aprendizado ao aluno.

Segundo Krasilchik (2004), a maneira unidirecional que é lecionada uma aula tradicional, gera o desinteresse dos alunos e consequentemente um baixo rendimento escolar, o que resulta em uma ineficiência no ensino. Diante disso, as aulas tradicionais passam a se dissociarem do cotidiano dos alunos, gerando dificuldades na hora de compreender a matéria, pois os estudantes podem não conseguir fazer relação com algo que lhes é comum, e o conteúdo acaba por se tornar abstrato.

Nesse contexto desenvolvendo-se aulas com a utilização de jogos, pode-se proporcionar uma educação que aponta o melhor desenvolvimento e atuação do aluno diante das disciplinas. $O$ lúdico deve ser visto como uma alternativa promotora da alegria quando os alunos estão jogando, assim, o mesmo se diverte e obtém a aprendizagem.

Assim, o objetivo do presente artigo propõe a aplicação de um jogo didático denominado "Baralho Ligante" que objetiva contribuir no processo de aprendizagem de conteúdos voltados para a Química.

\section{MATERIAIS E MÉTODOS}

\subsection{COMPONENTES DO JOGO}

- O baralho consistiu em um conjunto de 52 cartas.

- O primeiro conjunto contendo moléculas, compostos iônicos e retículos cristalinos de metais, com seus respectivos nomes.

- O segundo conjunto é formado por elementos químicos.

- O terceiro conjunto, cartas com o tipo de ligação.

- O baralho ainda é composto por quatro cartas coringa.

- Regras e andamento do jogo

\subsection{COMO JOGAR}

- O aluno deve formar um conjunto de quatro cartas, caracterizando o tipo da ligação química.

- A primeira carta corresponde ao tipo de ligação que é estabelecida, a segunda e a terceira correspondem aos elementos químicos que formam o composto.

- A quarta carta corresponde ao composto formado pela a união dos elementos em questão.

- A carta coringa pode substituir qualquer outra carta, desde que o aluno saiba explicar o porquê da substituição.

- A turma pode ser dividida em grupos de até oito alunos, sendo que cada jogador deve receber quatro cartas.

4a Semana de Química - IFRN, 2016 
- O restante das cartas deve ser colocado em um monte para futuras "compras".

- O primeiro jogador deve pegar uma carta no monte; se ela for útil para formar a ligação desejada, ele a mantém em mãos, descartando uma carta que não seja útil.

- O próximo jogador pode pegar a carta descartada, ou optar por uma nova carta no monte.

- As cartas são mostradas somente no fim da partida.

\subsection{VENCERÁ O JOGADOR QUE?}

O ganhador é aquele que completar primeiro um conjunto de quatro cartas que caracterize corretamente a ligação, de acordo com as regras mencionadas anteriormente.

\section{RESULTADOS ESPERADOS}

-Obter um novo jogo didático capaz de facilitar o ensino-aprendizagem dos alunos nas escolas;

- Incentivar o uso de materiais didáticos alternativos;

- Apresentar um meio alternativo para despertar o interesse dos alunos sobre os conteúdos de química;

- Formar recursos humanos na área de química/ensino de química.

\section{REFERÊNCIAS}

KRASILCHIK, M. Prática de ensino de biologia. 4. ed. São Paulo: Universidade de São Paulo, p.195, 2004. 